\title{
Demonstrating Technique to Teach Vocabulary Viewed From Student Intelligence
}

\author{
Muhammad Husnu \\ Study Program of English Language Education, Hamzanwadi University
}

\begin{abstract}
This research was aimed at finding out whether: (1) demonstrating technique was more effective than translation technique to teach vocabulary; (2) the students who had high intelligence have better vocabulary than those who had low intelligence; and (3) there was an interaction between teaching techniques and intelligence for teaching vocabulary. Designed as experimental study, it was conducted at the fourth grade of SDN 3 Pancor. The population of the research was the fourth grade students of SDN 3 Pancor in the academic year of 20152016. The samples were two classes. A cluster random sampling technique was used to take the samples. Each class was divided into two groups (the students who have high and low intelligence). Then, the techniques used to collect the data were an intelligence test and a multiple choice test. The vocabulary instruments were tried out to get valid and reliable items. The data were analyzed by using multifactor analysis of ANOVA $2 \times 2$ and Turkey test. Based on the findings, it can be concluded that in general demonstrating technique was more effective than translation technique to teach vocabulary. For the students who had high or low intelligence, demonstrating technique was more effective than translation technique to teach vocabulary. In accordance with the above result, the English teacher was expected to be able to select the appropriate teaching technique to teach vocabulary for the students who had high or low intelligence.
\end{abstract}

Key Words: Demonstrating Technique, Translation Technique, Vocabulary, Students' Intelligence

\section{Introduction}

English is one of the foreign languages for Indonesian students, which must be learnt at schools since junior high school level until university level. Besides it is also regarded as the first foreign language to be taught at elementary school as a local content.

English teaching involves four language skills: listening, speaking, reading, and writing. In teaching and learning process, there are two aspects that support four language skills above: grammar and vocabulary that are also taught in English teaching and learning process.

Teaching vocabulary is a very important part of language learning. Vocabulary is a list of words in alphabetical order in dictionaries as symbols of ideas which are needed by people to express and to communicate their ideas both from the first language and second language. 
In general, teaching vocabulary is not easy. There are many difficulties in teaching vocabulary, especially in elementary school students as the beginners. Based on the author's observation in teaching English at the fourth year of SD Negeri 3 Pancor, the author finds out that the mastery of English vocabulary of students is still low, although they have learnt English since the fourth year.

Many problems often appear during the teaching and learning process. The students' score of the vocabulary test is also low. It shows that the students' vocabulary mastery is poor. The causes of that problem are: the learner intelligence, the material is not interesting, the limited time and the equipment, and the technique of delivering materials is neither suitable nor interesting.

There are some factors that influence the result of teaching vocabulary, two of them are intelligence and teaching techniques. Most of the students' problems in learning vocabulary come from the students' intelligence. Intelligence is the cognitive capability to acquire and to apply the knowledge. The students' capability to acquire the vocabulary and to use it in real life will be influenced by the condition of students' intelligence. Crystal (1998: 362-378) states that one of the factors that contribute to satisfactory learning is intelligence besides motivation and opportunities.

Demonstrating strategy is believed by Indonesian teachers to serve this purpose. They find encouraging results when they use demonstrating technique in teaching vocabulary to children. It facilitates their learning of first, second or foreign language. The class is enlivened by the students' participations: raising hands, answering questions, contextualizing words, and other such reactions (Melani, 2004: 7).

Demonstrating technique presents speaking aloud and verbatim memorization. These occur in unison or in the form of echo recitation. In demonstrating technique, recitation is "chiming in" and is just the beginning of rehearsal. The teacher is listening in or eavesdropping to be able to give feedback. The purpose is for transferring to the long-term memory. Bower and Perry (2004: 42) state that speaking generates more electrical energy in the brain than just thinking about something.

Demonstrating technique is also a powerful way to cause over-learning occurring. Overlearning, that is, continuing to recite after something is memorized, creates deeper memory traces that make for longer retention (Banich and Smith, 2004: 72). Demonstrating technique builds on the two aforementioned strategies by promoting understanding, giving more recitation and rehearsal, and continuing the over-learning process. This strategy is more complex, however, in that it adds print to the learning dynamic. The recitation is still oral but the child is now looking at and pointing to the print.

Three essential effects of demonstration in teaching effectively are: (1) an attractive classroom and a pleasant classroom atmosphere; (2) a teacher with a dynamic personality who is able to act out the materials and motivate the students to learn; and (3) a state of relaxed alertness in the students (Krashen, 1982: 143).

Demonstration technique is very useful in teaching vocabulary for students at the beginners' level to encourage and motivate the students to learn the language, as stated by Coppen (1969: 88) "The purpose of demonstration is to provide a stimulus which will elicit a 
particular response from the learner. Demonstration technique represents some actions and in order to learn the appropriate words to describe the action itself.

Translation comes from an old Latin verb: transferre, and the term for translator is interpres (a person who interferes, who does not necessarily communicate honestly what he/she understands). Toury (1995: 72) states that translation is communication between messages integrated in a given linguistic-cultural system, that means they are regulated by norms and through them a society controls the importation and exportation of its culture.

The characteristics of translation technique are: (1) learning a language in order to be able to read; (2) focusing on reading and writing, not on the oral skills; (3) learning vocabulary words through bilingual lists; (4) the more sentences one translates, the better; and (5) this technique does not require much from the teacher and the student is passive.

Intelligence is a complex topic. There is still no standard definition of intelligence. It has led some to believe that intelligence may be approximately described but cannot be fully defined. In many cases the different definitions of intelligence actually say the same thing but in different words. The definitions of intelligence based on many dictionaries source, encyclopedias, and psychologists are stated below.

There are some definitions of intelligence as follows: intelligence is (1) "The capacity to acquire and apply knowledge." (The American Heritage Dictionary, fourth edition, 2000); (2) "The ability to use memory, knowledge, experience, understanding, reasoning, imagination and judgment in order to solve problems and adapt to new situations" (All Words Dictionary, 2006); (3) "The ability to learn, understand and make judgments or have opinions that are based on reason." (Cambridge Advance Learner's Dictionary, 2006); (4) "The ability to learn facts and skills and apply them, especially when this ability is highly developed." (Encarta World English Dictionary, 2006); (5) "Capacity for learning, reasoning, understanding, and similar forms of mental activity; aptitude in grasping truths, relationships, facts, meanings, etc" (Random House Unabridged Dictionary, 2006); (6) "The ability to learn, understands, and thinks about things." (Longman Dictionary or Contemporary English, 2006); (7) "The ability to learn or understand or to deal with new or trying situations: ... the skilled use of reason (2) the ability to apply knowledge to manipulate one's environment or to think abstractly as measured by objective criteria (as tests)" (Merriam-Webster Online Dictionary, 2006); (8) "The ability to acquire and apply knowledge and skills." (Compact Oxford English Dictionary, 2006); (9) "The ability to learn and understand or to deal with problems." (Word Central Student Dictionary, 2006); (10) "The capacity to learn, reason, and understand." (Wordsmyth Dictionary, 2006).

This research was aimed at finding out whether demonstrating technique is more effective than translation technique to teach vocabulary for the fourth grade students of $S D$ Negeri 3 Pancor, whether the students having high intelligence have better vocabulary than those having low intelligence for the fourth grade students of SD Negeri 3 Pancor, and whether there is an interaction between the teaching techniques and students intelligence. 


\section{Method}

This research is experimental study with a quantitative approach. Fraenkel and wallen(1993: 240) state that experimental study is one of the most powerful research methodologies, because it is the best way to establish cause and effect relationship between variables. Besides that, it is the only type of research that directly attempts to influence a particular variable.

Referring to this research, the writer chose the experimental research method because this research was related to the effectiveness of teaching techniques used as the independent variables and intelligence as the attribute variable in teaching vocabulary for the fourth grade students of SDN 3 Pancor. The research design used in this research was a simple factorial design. This research involved three kinds of variables namely independent variables, dependent variable, and attribute variable. The independent variable of this research is the teaching techniques. The teaching techniques are the factors of this study which are manipulated, measured and selected to know the effect and the relationship to the phenomenon investigated. The teaching techniques used in this study were demonstrating technique and translation techniques. These two different techniques were related to two groups of students. In this way, the demonstrating group of students functioned as an experimental group and translation group of students functioned as a control group.

Then, the dependent variable of this research is the students' vocabulary of the fourth grade students of SDN 3 Pancor in the academic year of 2015-2016. The attribute variable of this study is students' intelligence. This variable is also assumed as the secondary independent variable to the phenomenon investigated. In this study the writer is interested in investigating the effect of independent variable $(\mathrm{X})$ or teaching techniques on dependent variable (Y) or vocabulary, in which the relationship between $\mathrm{X}$ and $\mathrm{Y}$ is influenced by the attribute variable $(Z)$ or students intelligence. Furthermore, this study was conducted at the fourth grade students of SDN 3 Pancor in the academic year of 2015-2016. Then, the research was conducted on November up to April 2011.

The population of this study was all of the fourth grade students of SDN 3 Pancor in the School Year of 2010. The fourth grade students of SDN 3 Pancor were divided into three classes; those were IV-A, IV-B, and IV-C which consisted of 90 students.

The writer decided to take only 60 students (30 students from IV-A and 30 students from IV-B) or two classes from all of population as the sample of this study. In dividing each of the class into the group of high and low intelligence, the writer took 15 students who had high intelligence and 15 students who had low intelligence from grade IV-A (Experimental class). Furthermore, the writer took 15 students who had high intelligence and 15 students who had low intelligence from grade IV-B (Control class).

In this study, the researcher used objective tests in the form of multiple choices related to the material and the topic provided. Intelligence test was conducted by lentera hati foundation to know the student intelligence and vocabulary test was applied to know the students' vocabulary. 
The technique used in analyzing the data of this study was descriptive and inferential analysis. Descriptive analysis was used to know the mean, median, mode, and standard deviation of students' scores in writing and questionnaire answered by involving all variables of this study. In this study the researcher applied multifactor analysis of variance (ANOVA).

The Design of $2 \times 2$ ANOVA

\begin{tabular}{|c|c|c|}
\hline $\begin{array}{r}\text { Teaching } \\
\text { Techniques }\end{array}$ & $\begin{array}{l}\text { Demonstrating Technique } \\
\qquad \mathrm{A}_{1}\end{array}$ & $\begin{array}{l}\text { Translation } \\
\text { Technique } \\
\mathrm{A}_{2}\end{array}$ \\
\hline $\begin{array}{l}\text { High Intelligence } \\
\left(\mathrm{B}_{1}\right)\end{array}$ & $\begin{array}{l}\text { First group Students } \\
\left(\mathrm{A}_{1} \mathrm{~B}_{1}\right)\end{array}$ & $\begin{array}{l}\text { Second group Students } \\
\left(\mathrm{A}_{2} \mathrm{~B}_{1}\right)\end{array}$ \\
\hline Low Intelligence $\left(\mathrm{B}_{2}\right)$ & $\begin{array}{l}\text { Third group Students } \\
\qquad\left(\mathrm{A}_{1} \mathrm{~B}_{2}\right)\end{array}$ & $\begin{array}{l}\text { Fourth group Students } \\
\qquad\left(\mathrm{A}_{2} \mathrm{~B}_{2}\right)\end{array}$ \\
\hline
\end{tabular}

Then, Tukey test was used to know the difference between two teaching techniques and the mean score obtained is used to know which technique is more effective to teach vocabulary, whether demonstrating technique or translation technique.

\section{Results and Discussion}

Based on the result of analysis, it was found the data of $A_{1}$ shows that the score is 17 up to 29 . The mean is 23.5 , the mode is 23.5 , the median is 23.6 and the standard deviation is 3.37 , the data of $\mathrm{A}_{2}$ shows that the score is 11 up to 27 . The mean is 19.43 , the mode is 21.8 , the median is 21.8 , and the standard deviation is 5.75 , the data of $\mathrm{B}_{1}$ shows that the score is 11 up to 29 . The mean is 23.01 , the mode is 24.6 , the median is 24.3 , and the standard deviation is 3.82 , the data of $\mathrm{B}_{2}$ shows that the score is 11 up to 27 . The mean is 19.4 , the mode is 19.5 , the median is 19.5 , and the standard deviation is 5.28 , the data of $\mathrm{A}_{1} \mathrm{~B}_{1}$ shows that the score is 17 up to 29 . The mean is 24.25 , the mode is 23.7 , the median is 24.3 and the standard deviation is 3.12, the data of A1B2 shows that the score is 17 up to 27 . The mean is 22.56 , the mode is 21 , the median is 22.16 and the standard deviation is 3.45 , the data of A2B1 shows that the score is 11 up to 27 . The mean is 22.96 , the mode is 23.95 , the median is 24.75 and the standard deviation is 4.40 , and the data of A2B2 shows that the score is $11 \mathrm{up}$ to 27 . The mean is 16 , the mode is 16.5 , the median is 14.25 , and the standard deviation is 4.89. It was also found that the data was normal because $\mathrm{L}_{\mathrm{o}}$ (L obtained) is lower than $\mathrm{L}_{\mathrm{t}}(\mathrm{L}$ table) at the level of significance $\alpha=0.05$. L stands for Lilliefors and the data was homogenous because $\chi_{0}^{2}(6.809117)$ is lower than $\chi_{\mathrm{t}}$ at the level of significance $\alpha=5 \%$ (7.81). So $\chi_{\mathrm{o}}^{2}<\chi_{\mathrm{t}}(6.809117<7.81)$. Furthermore, based on the result analysis by using $2 \times 2$ 
ANOVA and Tukey test, it was found that $\mathrm{H}_{\mathrm{o}}$ was rejected because $\mathrm{F}_{\mathrm{o}}>\mathrm{F}_{\mathrm{t}}\left(\mathrm{F}_{\mathrm{o}}\right.$ is higher than $\mathrm{F}_{\mathrm{t}}$ ) and there was a significant difference between the two groups (Group A and group B).

After knowing the histogram and polygon of each group, the researcher analyzes the normality and homogeneity of the data. The normality of the data is to know whether the sample is in normal distribution and the homogeneity of the data is to know whether data are homogeneous.

The data, which have been collected need to be analyzed orderly. It means to answer the problems as follows: (1) Is demonstration technique more effective than translation technique to teach vocabulary for the fourth grade students? (2) Do the students who have high intelligence have better vocabulary mastery than those who have low intelligence for the fourth grade students? (3) Is there any interaction between teaching techniques and intelligence to teach vocabulary for the fourth grade students? All of them answered by the analysis of the data. The researcher analyzed the data using multifactor analysis and turkey test.

The result of data analysis will be consulted to $\mathrm{F}$ table at the significance level $a=0.05$ to know whether the result was significant or not. If the result of $\mathrm{F}_{\mathrm{o}}$ is higher than $\mathrm{Ft}$, it means that the null hypothesis is rejected and the result of the research is significant. Based on the table of a 2 x 2 multifactor analysis of variance above it can be concluded that:

1. Because $F_{o}$ between columns (14.00512) is higher than $F_{t}(.05)$ (4.20), the difference between columns is significant. Because the mean score of students taught using demonstrating technique (23.33333) is higher than that of students taught using translation technique (19.43333), it can be concluded that teaching vocabulary using demonstrating technique is more effective teaching technique than translation technique for teaching vocabulary.

2. Because $F_{o}$ between rows (17.55729) is higher than $F_{t}(.05)(4.20)$, the difference between rows is significant. Because the mean score of students having high intelligence (23.56667) is higher than the mean score of students having low intelligence (19.2), it can be concluded that students having high intelligence is better than students having low intelligence.

3. Because $F_{o}$ interaction (5.754896) is higher than $F_{t}(.05)(4.20)$, there is an interaction effect between the two variables, the teaching techniques and intelligence for teaching vocabulary. It can be stated that the effectiveness of teaching techniques depends on the high or low students' intelligence.

Based on the tuckey test, it can be concluded that:

1. Because $q_{o}$ between columns $\left(A_{1}-A_{2}\right)$ (5.292469266) is higher than $q_{t}(0.05)$ (3.00), the difference between columns is significant. Because the mean score of students taught using demonstrating technique (23.33333) is higher than that of students taught using translation technique (19.43333), it can be concluded that demonstrating technique is more effective than translation technique to teach vocabulary.

2. Because $\mathrm{q}_{\mathrm{o}}$ between rows $\left(\mathrm{B}_{1}-\mathrm{B}_{2}\right)$ (5.925756186) is higher than $\mathrm{q}_{\mathrm{t}}(\mathbf{0 . 0 5})$ (3.00), the difference between rows is significant. Because the mean score of high intelligence 
(23.56667) is higher than the mean score of low intelligence (19.2), it can be concluded that the students who have high intelligence have better vocabulary than those who have low intelligence

3. Because qo between A1B1-A2B1 (1.343404428) is lower than qt (0.05) (3.26), the difference between A1B1 - A2B1 is not significant.

4. Because $q_{o}$ between $A_{1} B_{2}-A_{2} B_{2}$ (6.141277386) is higher than $q_{t}(0.05)$ (3.26), the difference between $A_{1} B_{2}-A_{2} B_{2}$ is significant. Because the mean score of the students having high intelligence who were taught using demonstrating technique (22.4) is higher than the students having high intelligence who were taught using demonstrating technique (16), it can be concluded that demonstrating technique is more effective than translation technique.

Based on the result of tuckey test at point 3 and 4 above, it can be concluded that there is no interaction between teaching techniques and intelligence to teach vocabulary because demonstrating technique is more effective than translation technique for students who have high intelligence or low intelligence.

\section{Conclusion}

Based on the result of the data analysis presented in chapter IV, it can be concluded that the finding of the research are: Using demonstrating technique is better than translation technique for teaching vocabulary at the fourth grade students of SDN 3 Pancor in the school year of 2015-2016. The students having high intelligence have better vocabulary than the students having low intelligence vocabulary at the fourth grade students of SDN 3 Pancor in the school year of 2015-2016. There is no interaction between teaching technique and intelligence in teaching vocabulary at the fourth grade students of SDN 3 Pancor in the school year of 2015-2016.

Based on the finding above, it can be concluded that in general Demonstrating technique is an effective teaching technique to teach vocabulary. The level of student vocabulary mastery is determined by the level of student intelligence and teaching technique.

\section{References}

Beck, Issabel, et al. (2004). Bringing words to life. New York: the Guilford press.

Broughton, Geoffrey, et al. (2003).Teaching English as foreign language. New Jersey: routladge

Chesla, Elizabeth (2004). Just in time Vocabulary. New York: Learning express.

Coroselli, Marlene (2006). 500 Creative Classroom Techniques for teacher and trainers. New Jersey: HRD press

Doff, Adrian, et al. (2004). Language Link, grammar and vocabulary for self study. New Jersey: Cambridge.

Elfrieda, et al. (2005). Teaching and Learning vocabulary. New Jersey: Lawrence associates. 
Finnie and Daniele (2003). Vocabulary Activities (Elementary). London: color press.

Gairn and Redman (2006). Working with word. New Jersey: Cambridge university press

Jack C. Richard and Theodore S. Rodger (1986). Approaches and methods in language teaching. Cambridge University Press

James Coady and Thomas Huckin (1997). Second Language Vocabulary Acquisition, Cambridge University Press

Kenworthy, Joanne (1988). Teaching English pronunciation. New Jersey:

Longman

McCarty, Michael, et al. (1999). English collocation. New York: Cambridge

Peter Watcyn-Jones (1994). Target Vocabulary. New Zealand

Purland, Matt (2005). Big resource book. England: English banana.

Purland, Matt (2008).Talk a lot spoken English course elementary book 1. England: English banana.

Redman, Stuart, et al. (2002). Activating Vocabulary. New York: Cambridge

Richards and Christine (2002). English through pictures. New York: Washington square press

Robinson, Anne (2002). Fun for Flyer. New York: Cambridge.

Suzanna (1997). With Grammar Communicative. Activities for the Azar grammar series. New Jersey: Prentice hall inc.

Scott and Lisbeth (2006). Teaching English to Children. New York: Longman.

Steven and Bill (2005). Handbook of vocabulary Teaching Strategies. New Jersey: Longman

Steven and William (2006). Teaching word Meaning. New jersey: Laurence Erlbaum associates,inc.

Tomalin, Mary (2002). Instant Lesson 2 Elementary. England: Associated Companies.

Thornbury, Scott (2004). How to teach vocabulary. New Jersey: Cambridge,

Wolfe, Harry K. (1890). On the Color-Vocabulary of Children. University of Nebraska Lincoln.

Woodword, Julie (2004). Vocabulary activities. New York: Cambridge. 